MATEC Web of Conferences 22,01049 (2015)

DOI: $10.1051 /$ matec conf/ 20152201049

(C) Owned by the authors, published by EDP Sciences, 2015

\title{
A Study of Scenic Spot Living Facility Recommendation Based on Col- laborative Filtering
}

\author{
Wenbiao Luo \\ Economic and Trade Department,Guangzhou Vocational College of Science and Technology, Guangzhou, Guan \\ gdong, China
}

ABSTRACT: For the collection of massive complex information, the collaborative filtering system can work as a highly efficient information screening tool. It can recommend reasonable information reserve with multi angles according to the living service facility information of the scenic spots. The collaborative filtering system can collect information and forecast rating results based on users' preference. According to different recommendation goals, the collaborative filtering system can recommend results for user feedback and give feedback of the recommendation results in various forms.

Keywords: collaborative filtering system, filtering system, living service facilities of scenic spots

\section{INTRODUCTION}

There's plenty of tourism information contained in computer networks. With the improvement of people's living standards, the tourist industry has experienced unprecedented development. The living service facilities around scenic spots are the main places for tourists to take a rest during travelling. The so-called "Donkey Friends" in the network can provide a great deal of information for us. However, it is not easy to find the most appropriate information we need from the complex tourism information.

During the process of filtering information, the collaborative filtering system has been gradually applied online in many large-scale tourism websites, such as Qunar.com and Kuxun.cn. On the websites, infor- mation of hotels, accommodation, catering and entertainment which are within our planned travelling range will be listed online. And thus, appropriate living facilities for both tourist groups and self-driving travels can be found. It will not only make our travels more relaxing, but will also improve our travelling quality. Therefore, the collaborative filtering system is an important means for information screening.

Compared with information indexing, filtering of indexed information is more important. Due to the diversity of information categories, information quality is in unevenness. During the computing process of the collaborative filtering system, the system can avoid repeated inquiry, eliminate gibberish, and offer personalized options.

\begin{tabular}{|c|c|c|c|c|c|c|c|c|}
\hline Tourists/Scenic Spots & No. 1 & No. 2 & No. 3 & No. 4 & No. 5 & No. 6 & No. 7 & No. 8 \\
\hline$i_{1}$ & 4 & & 5 & 4 & & & 5 & \\
\hline$i_{2}$ & 1 & & & & & & & \\
\hline$i_{3}$ & 3 & 4 & 3 & 4 & & & & \\
\hline$i_{4}$ & 5 & 5 & & & & 4 & & \\
\hline$i_{5}$ & 5 & & 3 & 5 & & & 4 & \\
\hline$i_{6}$ & 5 & & & 4 & 5 & 4 & 4 & 5 \\
\hline$i_{7}$ & 4 & & & 3 & & & & \\
\hline$i_{8}$ & 5 & & & & 3 & & & \\
\hline$i_{9}$ & 1 & & 4 & & & & 3 & \\
\hline$i_{10}$ & 5 & 4 & & 5 & & 3 & & \\
\hline
\end{tabular}

This is an Open Access article distributed under the terms of the Creative Commons Attribution License 4.0, which permits unrestricted use, distribution, and reproduction in any medium, provided the original work is properly cited. 


\section{MATEC Web of Conferences}

\section{THE ESTABLISHMENT OF COLLABORATIVE} SYSTEM

Some tourists gave ratings online to some scenic spots in Chengdu. The highest rating for this evaluation is 5 This paper has made random arrangement to these ratings and got Table 1 shown as below.

Take tourism in Chengdu as an example. The set scenic spots for tourism include the followings: No.1 is Songpan; No.2 is Huanglong Temple; No. 3 is Jiuzhaigou Valley; No. 4 is Jinli; No. 5 is Du Fu's Thatched Cottage; No. 6 is Mount Qingcheng of Dujiang Dam; No. 7 is Tianfu Square; No. 8 is Huanhua Brook; No. 9 is Wenshu Monastery; and No. 10 is Temple of Marquis.

2.1 Solving steps of the collaborative filtering algorithm

(1) This paper firstly establishes the rating matrix to calculate the similarity matrix $S$ and the association degree matrix $G$ among the scenic spot living facilities.

(2) In order to establish the rating item set $I$ for users, read the neighbor set of each item $k$ from $G$ :

$$
N_{i}=\left\{i_{1}, i_{2}, \cdots, i_{k}\right\}
$$

Screen the preselected item set $C^{\prime}$

(3) Delete the items which already exist in the item set $I$ from $C^{\prime}$ and obtain the candidate item set $C$

(4) Predict users' ratings to the items.

(5) Sort the obtained rating results.

2.2 The Establishment of the Collaborative Filtering Algorithm Rating System

Table 2 The Establishment of the Rating System $T_{i}$

\begin{tabular}{lllll}
\hline $\begin{array}{l}\text { Preference } \\
\text { Degree }\end{array}$ & \multicolumn{4}{l}{ Rating Extent Setting } \\
\cline { 2 - 5 } Very good & 0 & $60-60$ & $80-90$ & $90-100$ \\
Good & 0 & 0 & 0.05 & 0.95 \\
Normal & 0.05 & 0.9 & 0.9 & 0.05 \\
Bad & 0.95 & 0.05 & 0 & 0
\end{tabular}

Establish the following formula according to the rating system:

$$
M A E=\frac{1}{N} \sum_{i-1}^{N}\left|P_{i}-T_{i}\right|
$$

$P_{i}$ refers to the predicted value obtained in the prediction of scenic spot living facilities; and $T_{i}$ refers to the tourists' ratings to the scenic spot living facilities as shown in Table 2.

Conduct random screening of the information shown in Table 1 and obtain Table 3 shown as below.

\begin{tabular}{llllll}
\multicolumn{6}{l}{ Table 3 Original Matrix } \\
$\begin{array}{l}\text { Tourists/Scenic } \\
\text { Spots }\end{array}$ & No. 1 & No. 2 & No. 3 & No. 4 & No. 6 \\
\hline$i_{3}$ & 3 & 4 & 3 & 4 & \\
$i_{4}$ & 5 & 5 & & & 4 \\
$i_{5}$ & 5 & & 3 & 5 & \\
$i_{6}$ & 5 & & & 4 & 4 \\
$i_{10}$ & 5 & 4 & & 5 & 3 \\
\hline
\end{tabular}

\begin{tabular}{llllll}
\multicolumn{2}{l}{ Table 4 Matrix $S$} & \multicolumn{5}{l}{} \\
\hline $\mathrm{G}$ & $\mathrm{A}$ & $\mathrm{B}$ & $\mathrm{C}$ & $\mathrm{D}$ & $\mathrm{E}$ \\
\hline$U_{1}$ & 3 & 4 & 3 & 4 & 0 \\
$U_{2}$ & 5 & 5 & 0 & 0 & 4 \\
$U_{3}$ & 5 & 0 & 3 & 5 & 0 \\
$U_{4}$ & 5 & 0 & 0 & 4 & 4 \\
$U_{5}$ & 5 & 4 & 0 & 5 & 3 \\
\hline
\end{tabular}

Establish the matrix, in which

$$
S=U_{a} \times U_{a}^{T}
$$

As shown in Table 5

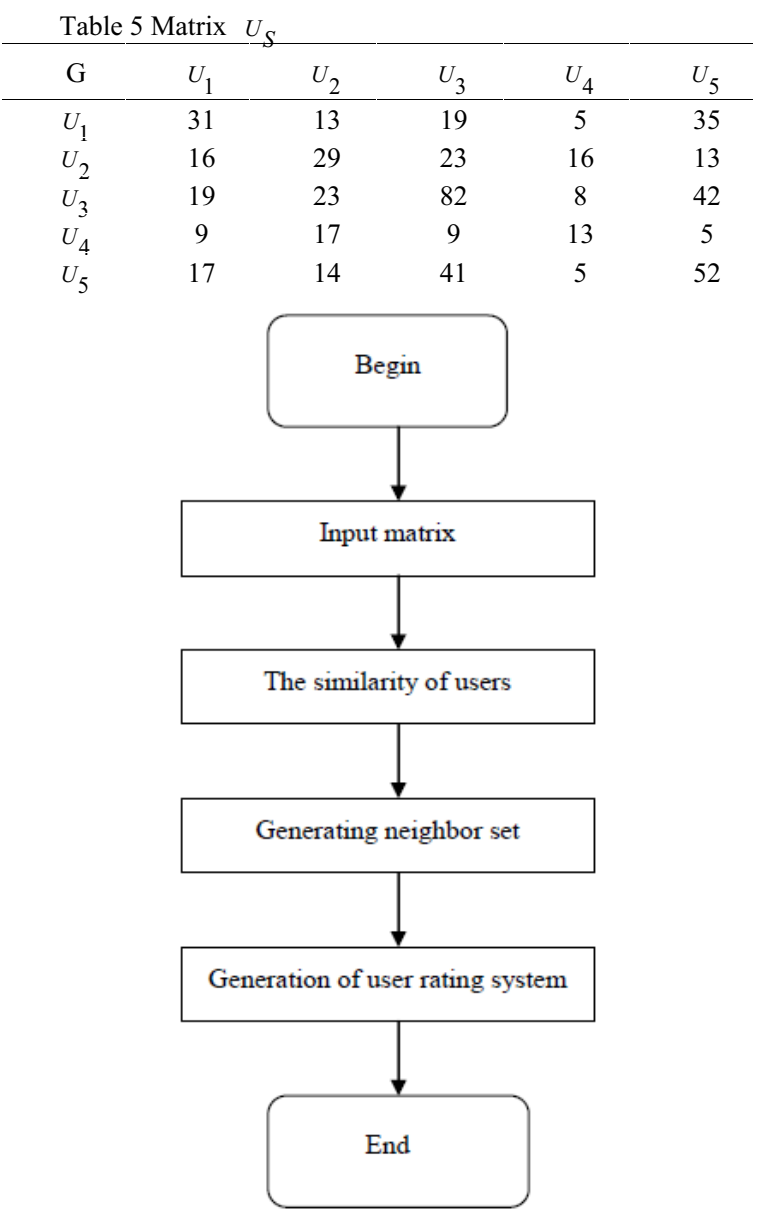

Figure 1. Collaborative Algorithm Flow Chart 


\section{ICETA 2015}

Establish matrix $U_{S}$ sharing the same size with matrix $\mathrm{S}$

$$
U_{S}(i, j)=S(i, j) /(S(i, i) \times S(j, j))^{1 / 2}
$$

Obtain matrix $U_{S}$ as shown in Table 5.

\begin{tabular}{clllll}
\multicolumn{6}{c}{ Table 6. Comparison Matrix } \\
\hline $\mathrm{G}$ & $U_{1}$ & $U_{2}$ & $U_{3}$ & $U_{4}$ & $U_{5}$ \\
\hline$U_{1}$ & 1 & 0.45 & 0.35 & 0.38 & 0.90 \\
$U_{2}$ & 0.45 & 1 & 0.48 & 0.78 & 0.33 \\
$U_{3}$ & 0.35 & 0.48 & 1 & 0.23 & 0.64 \\
$U_{4}$ & 0.38 & 0.78 & 0.23 & 1 & 0.18 \\
$U_{5}$ & 0.90 & 0.33 & 0.64 & 0.18 & 1 \\
\hline
\end{tabular}

Conduct rating examination to the matrix

$$
U_{S}=\left\{\begin{array}{ccccc}
1 & 0.45 & 0.35 & 0.38 & 0.90 \\
0.45 & 1 & 0.48 & 0.78 & 0.33 \\
0.35 & 0.48 & 1 & 0.23 & 0.64 \\
0.38 & 0.78 & 0.23 & 1 & 0.18 \\
0.9 & 0.33 & 0.64 & 0.18 & 1
\end{array}\right\}
$$

Normalization processing

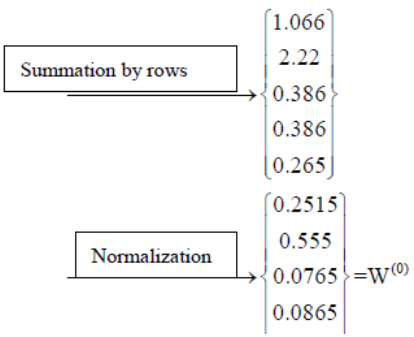

Obtain:

$$
\lambda_{\max }^{(0)}=4.038
$$

The judgment matrix can be calculated in a similar way.

Apply coincidence indicators for examination: $C I=\frac{\lambda \max ^{-n}}{n-1} \quad C R=\frac{C I}{R I}$

Obtain the judgment matrix $A, \lambda^{(0)}{ }_{\max }=4.073, R I=0.9$

$$
C I=\frac{4.073-4}{4-1}=0.24
$$

$C R=\frac{C I}{R I}=\frac{0.024}{0.90}=0.027<0.1 \quad$ means the inconformity examination for $\mathrm{A}$ is effective and the motion is within the approved range.

\subsection{Application of threshold value neighboring method in finding similarity}

Threshold value neighboring method is to find similarity by dividing area coverage, such as dividing the similarity by setting certain radius; or using the nearest neighboring method for summarizing the sets within a certain range.

As regular hexagon is the closest shape to the ideal circle. It can effectively cover the required area in the most reasonable way. Based on the above, the division structure should start from the center of the regular hexagon and extend outwards shown in Fig. 2.

Table 7. RI Value

\begin{tabular}{lrrrrrrrrrrrrr}
$\mathrm{n}$ & 1 & & 2 & 3 & 4 & 5 & 6 & 7 & 8 & 9 & 10 & 11 \\
\hline $\mathrm{RI}$ & 0 & 0 & & 0.58 & 0.90 & 1.12 & 1.24 & 1.32 & 1.41 & 1.45 & 1.49 & 1.51
\end{tabular}

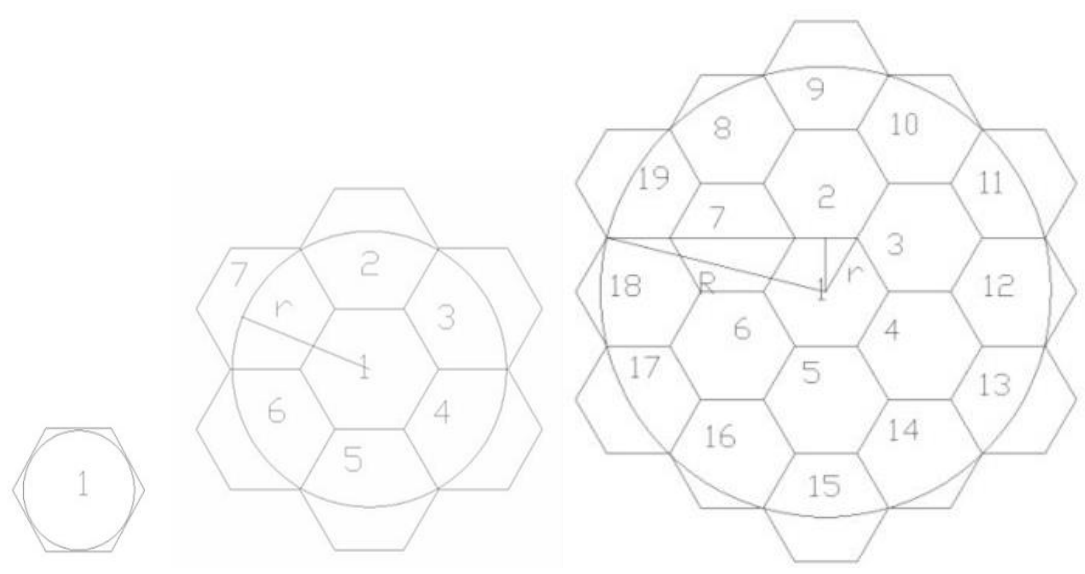

Figure 2. Expansion Diagram of the Coverage Field 


\section{MATEC Web of Conferences}

We can find the relationship between the diameter $\mathrm{d}$ and number $\mathrm{N}$ :
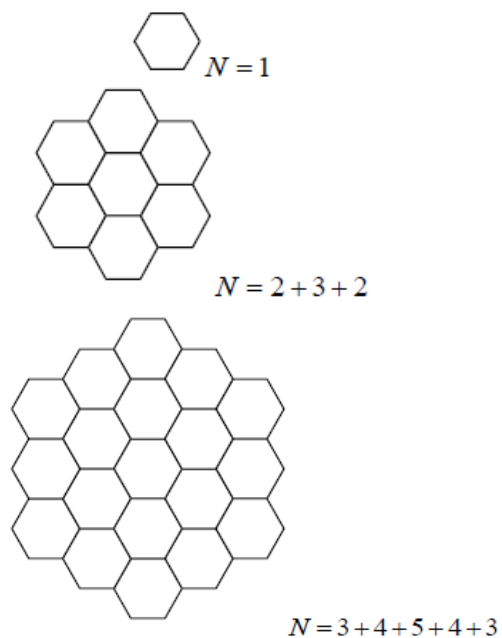

2.4 Application of K-nearest Neighboring Method in Finding Similarity

Use the K-nearest neighboring method to find similar ity as shown in the table below. For example, find the scenic spots close to No. 1 scenic spot.

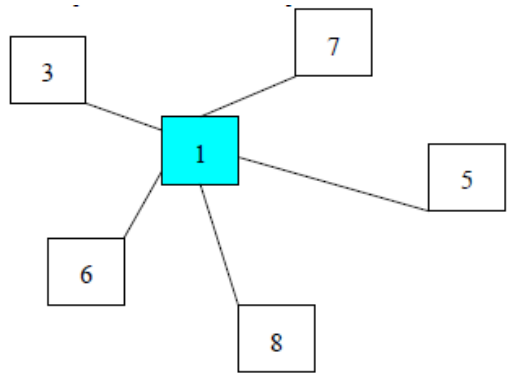

system can manifest good information screening capability. By abstracting many tourists' ratings given online on the ten scenic spots in Chengdu, this paper offers recommendation on scenic spot living facilities based on the collaborative filtering algorithm. As there're differences existing in users' requirement degrees, the ratings obtained in this paper are not the same, which shows that the collaborative system can well fit users' goals.

\section{REFERENCES}

[1] Zhang J.B. 2011. Study and Realization of the Collaborative Filtering Algorithm of Recommendation System. Beijing: Beijing University of Posts and Telecommunications.

[2] Hou X.H. \& Wen Y.M. 2014. Scenic spot recommendation based on collaborative filtering. Computing Technology and Automation. (4): 116-119

[3] Li C. 2009. Research of Bottleneck Forecasting in the Collaborative Filtering of E-commerce Recommendation System. Hefei University of Technology.

[4] Chen J. \& Yin J.2007. Collaborative filtering recommendation algorithm based on influencing set. Software Journal, 18(7): 1685-1694.

[5] Huang C.G., Yin J. \& Wang J. et al. 2010. Collaborative Filtering Recommendation Algorithm with Uncertain Adjacent Neighbors. Chinese Journal of Computers, 33(8): 1369-1377.

[6] Wang X.F., Chen M. \& Li X.T.2012. Research and design of tour recommendation system based on restrictions. Computer Technology and Development, 22(2): 141-145.

[7] Yu X. 2009. Study of Recommendation Methods Based on Collaborative Filtering Technology. Tianjing: Tianjin University.

[8] Ma H.W., Zhang G.W. \& Li P. 2009. Review of collaborative filtering recommendation algorithm. Mini-Micro Computer Systems, 30(7): 1282-1288.

Figure 3. Diagram of K-nearest Neighboring Method Application in Finding Similarity

For any user $\mathrm{u}$, a neighbor set $\mathrm{Yi}=\left\{\mathrm{Y}_{1}, \mathrm{Y}_{2}, \mathrm{Yk}>\mathrm{Y}_{\mathrm{i}}\right.$, $\mathrm{u}$ doesn't belong to $\mathrm{Yk}\}$ will be generated. It is sorted by the degree of similarity (from great to little) among which $k \leq \sqrt{\text { User amount of the test set }}$.

\section{CONCLUSION}

This paper studies the recommendation on scenic spot living facilities provided by the collaborative filtering system. During the analysis process, the collaborative 